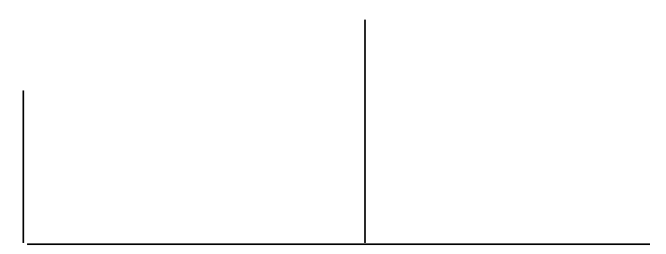

Rev. Latinoam. Psicopat. Fund., IX, 2, 318-338

\title{
O Acompanhante Terapêutico "em ação" no campo público da assistência em saúde mental
}

\author{
Renata Simões Velozo \\ Octávio Domont de Serpa Júnior
}

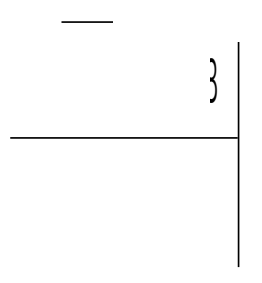

Este estudo visa refletir sobre o acompanhamento terapêutico como uma modalidade de assistência destinada às pessoas com transtornos mentais. A partir de suas origens e do seu desenvolvimento ao longo da história, buscamos construir articulações possíveis desta prática com as atuais diretrizes éticas e clínicas das políticas públicas brasileiras, visando enxergá-la como opção estratégica a ser inserida na assistência pública em saúde mental.

Palavras-chave: Acompanhamento terapêutico, atenção psicossocial, integralidade, território 
Com o desenvolvimento da Reforma Psiquiátrica no Brasil, a partir dos anos 1980 (Delgado, 1992), sobretudo após as Conferências Nacionais de Saúde Mental (1987, 1992, 2001), culminando com a promulgação da Lei 10.216 de abril de 2001, estamos assistindo, no âmbito do Sistema Único de Saúde, ao processo de consolidação de uma política de saúde mental que afirma os direitos dos adultos, crianças e adolescentes que vivem com problemas mentais graves, e também àqueles que fazem uso prejudicial de álcool e outras drogas. Nestes primeiros anos do século XXI, programas federais, estaduais e municipais estão redirecionando definitivamente o modelo de assistência em saúde mental no Brasil, sendo notável a redução de leitos psiquiátricos e a implantação simultânea dos Caps - os Centros de Atenção Psicossocial, ${ }^{1}$ e dos Serviços Residenciais Terapêuticos. Desta forma, não cessam discussões acerca de novas estratégias inclusivas que venham garantir os direitos e a circulação das pessoas que sofrem de transtornos mentais no cotidiano da cidade, fora dos contextos institucionais e hospitalares. A ampliação de recursos intermediários entre a internação hospitalar e as consultas ambulatoriais têm sido a tônica dos últimos anos (Teixeira, 1997, p. 4). O tema deste estudo tornase pertinente, na medida em que o acompanhamento terapêutico é uma prática suplementar a um tratamento em curso que oferece a possibilidade de assistência em diferentes espaços e no deslocamento físico entre pessoas e lugares. Entendemos que esta pode servir como uma eficiente ferramenta clínica na construção ou reconstrução de laços sociais, territoriais e familiares. Iremos abordar o contexto do surgimento do acompanhamento terapêutico, sua representatividade no desenrolar da história e suas possibilidades clínicas na terapêutica

1. Serviços públicos comunitários de assistência em saúde mental. 


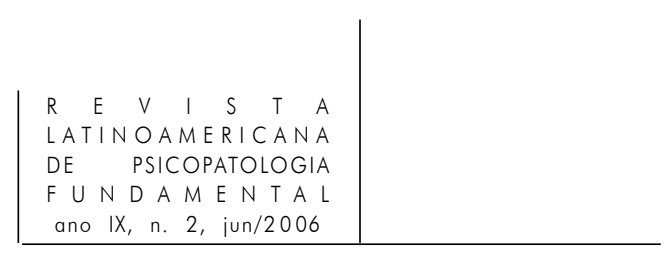

dos problemas mentais no atual contexto da Reforma Psiquiátrica Brasileira. Na travessia do sistema público de saúde, iremos pensar sobre os novos modos de cuidados e os novos dispositivos que compõem o cenário assistencial a partir dos conceitos: território e integralidade da assistência, com vistas à inclusão social. Em trânsito por diferentes lugares e serviços, iremos ver de que forma o acompanhante pode contribuir na conexão com o espaço urbano e entre o "dentro e fora” das instituições. Neste "circular pelo território", iremos analisar a plasticidade desta ferramenta clínica e a questão dos riscos que esta prática representa. Por fim, iremos verificar as diferentes dimensões que se revelam neste processo onde parte da tarefa é provocar o acaso, produzir encontros e acontecimentos.

\section{A história}

Embora não haja muito consenso entre os autores, o acompanhamento terapêutico teria nascido na Argentina, no período de 1971 a 1978, no Centro de Abordagens Múltiplas (CETAMP) em Buenos Aires (Mauer \& Resnizky, 1987). Recentemente, essas autoras lançaram uma atualização dessa obra, na qual consta uma entrevista com o dr. Eduardo Kalina, o então inventor do "amigo qualificado", abordando o nascimento dessa prática:

La historia sobre los acompañamientos terapéuticos ya tiene vida propia, ya existen otras historias y, sobretodo, hay historias de la historia. Los conocimientos son de todos y para todos (...). En 1970, creé el rol de "amigo calificado" como resultado de la necesidad de contar con más recursos para tratar adolescentes con problemas de adicción de drogas (...) los adictos no eran confiables para salir solos a la calle. (...) Eran necesarios "amigos calificados". Tenían que ser jóvenes vitales, fuertes, con cualidades especiales: ingenio, lealtad, una sólida convicción anti-drogas e fundamentalmente creatividad para lograr ser objetos pasibles de identificaciones positivas. (ibid., 2003, p. 109)

Segundo as autoras argentinas, a primeira função atribuída ao acompanhante terapêutico era "conter" o paciente psiquiátrico fora do contexto institucional ou das consultas médicas. Havia as seguintes premissas a serem seguidas pelo AT: ${ }^{2}$ representar o terapeuta; servir como um modelo de identificação; apresentar-se como uma figura empática; atuar como agente ressocializador; informá-lo sobre o mundo real e suas regras sociais; reforçar a capacidade criativa etc. (ibid.,

2. Iremos nos referir ao acompanhante terapêutico com a abreviação AT. 
1987, p. 40-2). A intenção principal do trabalho era certificar o dia-a-dia do paciente fora do contexto das consultas e ampliar o controle exercido pelo médico ou pela família, como descreve relato de Kalina.

No Brasil, o acompanhamento terapêutico tornou-se conhecido como uma modalidade de atuação que permitia uma aproximação diferenciada com pacientes portadores de transtornos mentais graves e que, em determinado momento da história, abriu um novo campo de trabalho para estudantes e profissionais de psicologia. Em uma prática de "saídas", passou a ser possível sair com o paciente pelo mundo exterior, buscando novas conexões, novos encontros nos espaços extramuros (Carrozzo, 1991, p. 12). A referência argentina, que a princípio serviu para nortear o trabalho dos primeiros auxiliares ou acompanhantes terminou por suscitar discussões e levantar diferenças fundamentais entre o trabalho proposto e a prática que veio se desenvolvendo em nosso contexto brasileiro.

Ainda à procura das origens desta prática, que seria antes um campo de intervenção na área de saúde mental do que uma técnica terapêutica específica (Reis, 1995, p. 5), buscamos incluir nesta pesquisa aspectos espaciais, territoriais e contextuais, visto que este agente "em trânsito" utiliza referências completamente diferentes daquelas que comumente lidamos em nossos consultórios. A história dessa assistência que se presta em circulação nos move para diferentes contextos e épocas. Tentaremos contá-la considerando que são os diferentes tempos e lugares que irão marcar as especificidades desta função.

Na América Latina nos anos 1960, começam a surgir instituições, a exemplo das experiências européias, chamadas comunidades terapêuticas. Conta Reis (1995) que, dado o grande intercâmbio que havia na época entre Buenos Aires e Porto Alegre, à semelhança do acompanhante argentino, surge no sul do Brasil a figura do atendente psiquiátrico na comunidade terapêutica Clínica Pinel (p. 8). Essa clínica particular oferecia um modelo alternativo de tratamento aos doentes mentais com regimes de internação ou "Hospital-dia". ${ }^{3}$ Os atendentes não tinham nenhuma preparação técnica ou acadêmica específica; eram jovens que se dispunham a conviver com os pacientes a fim de tornar mais ameno o clima da instituição. Em novembro de 1969, um grupo de psiquiatras com formação psicanalítica, inspirado nas experiências de Porto Alegre, inaugura na cidade do Rio de Janeiro a Clínica Vila Pinheiros. É neste espaço que irá surgir a figura não do atendente, mas do auxiliar psiquiátrico: um novo elemento da equipe técnica que terá por função acompanhar o paciente no cotidiano da vida na comunidade. Para garantir os ideais comunitários e as práticas assistenciais já existentes no sul

3. Neste tipo de regime, os pacientes que passavam o dia na comunidade terapêutica, e à tarde voltavam para suas residências. 


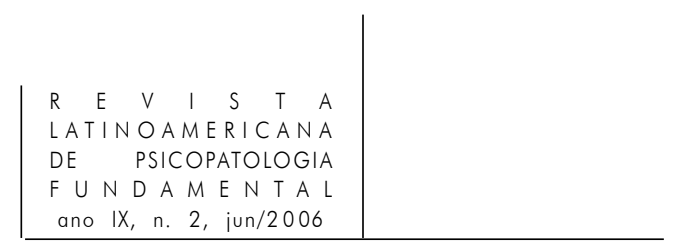

do Brasil, uma psiquiatra e quatro atendentes saem da Clínica Pinel para trabalhar na Vila Pinheiros (p. 31).

Vila Pinheiros irá caracterizar-se por ser uma instituição privada, de orientação psicanalítica, que prestará atendimento psiquiátrico como uma proposta alternativa no tratamento de pacientes psicóticos. Aos auxiliares cabia conviver com os pacientes, participar de reuniões, grupos e organizar comissões para realização de festas, atividades esportivas, jogos diversos, teatro, jornal etc. (Ibrahim, 1991, p. 44). Nesses espaços, menciona Reis (1995), foram criadas práticas experimentais onde era investigada a aplicabilidade da psicanálise no terreno das psicoses. O trabalho do auxiliar psiquiátrico, futuro acompanhante terapêutico representou, em determinado momento, a complexa convivência entre as concepções clássicas da psiquiatria acerca da loucura, as tentativas de se compreender o fenômeno psicótico pelo viés psicanalítico e a necessária reinserção do paciente no social. Conta o autor que no decorrer de seus oito anos de funcionamento, a Vila entra em declínio e não consegue manter o caráter "alternativo" idealizado por seus fundadores. Muitos pacientes jovens que haviam sido transferidos de outras instituições para se "curar", acabam permanecendo sem perspectiva de alta. Em 1976, a clínica encerra suas atividades com uma clientela cronificada e muitos problemas entre seus sócios (p. 91). Com o seu fechamento, os auxiliares psiquiátricos são convidados por psiquiatras e psicanalistas para estar com os seus pacientes fora do contexto institucional, em geral para auxiliar no manejo de situações de crise, evitando a internação hospitalar, garantindo-lhes “proteção” em “internações” domiciliares (p. 96).

É a partir deste momento que começam a se formar, na cidade do Rio de Janeiro, equipes de auxiliares psiquiátricos, formadas por psicólogos autônomos. A partir dos anos 1980, os auxiliares psiquiátricos decidem se designar como acompanhantes terapêuticos ou psicoterapêuticos. Tal mudança de nome se deu em razão de um novo lugar que esses profissionais desejavam adquirir diante de seus pacientes. Orientados pela clínica psicanalítica, buscavam privilegiar uma escuta do desejo dos sujeitos, e portanto do inconsciente, tendo a palavra como ferramenta de trabalho e o vínculo de confiança mútua estabelecido através da transferência (Ribeiro, 2002, p. 79). Como destaca Reis (1995), um dos grupos formados a partir dos "remanescentes" da Vila, era denominado EAP - Equipe de Acompanhantes Psiquiátricos, depois Psicoterapêuticos, e que mais tarde dissolveu-se, dando origem ao APSI - Grupo de Acompanhamento Psicoterápico - e ao Grão. Outro grupo, denominado GRAP - Grupo de Acompanhamento Psicoterapêutico - organizava-se em pequenos grupos que seguiam metas e estratégias construídas caso a caso durante as reuniões de equipe (p. 114).

Poderia neste momento seguir analisando a constituição destes grupos e a formação de outros que seguiram trabalhando na prática privada do exercício de 
acompanhamento terapêutico. Contudo, pensamos que é preciso contextualizar, em poucas linhas, o momento político em que se estava vivendo no Brasil. A saúde pública se encontrava privatizada, os hospitais psiquiátricos conveniados com a previdência abarrotados de pacientes em condições sub-humanas. Esta situação gera críticas e indignação. A partir dos anos 1980, o movimento pela luta antimanicomial ganha força em nosso país (Delgado, 1992). A partir desse período se precipita a Reforma Psiquiatra Brasileira que ocorre conjuntamente com o movimento de redemocratização do país. A partir daí, experiências inovadoras em psiquiatria começam a surgir consolidando um sólido movimento de transformação no campo público de assistência em saúde mental. Dentre elas, o trabalho realizado pela equipe do NAPS do município de Santos-SP (1989), do Centro de Atenção Psicossocial (CAPS) Prof. Luiz da Rocha Cerqueira, em São Paulo (1987). Essas experiências tiveram uma repercussão que serviram de inspiração para diversos outros projetos (Teixeira, 1997, p. 7). Em julho de 1989, ocorre no Instituto de Medicina Social da UERJ, Rio de Janeiro, o I Encontro Sobre o Tratamento das Psicoses em Instituição. Esse evento reuniu profissionais de diversas instituições, públicas e privadas, para, em um esforço coletivo, fazer avançar as questões relativas às suas práticas institucionais no tratamento das doenças mentais. ${ }^{4}$ Nessa oportunidade foi discutida de forma inaugural a possibilidade de inserção dos acompanhantes terapêuticos na rede pública, ${ }^{5}$ como recurso intermediário entre o ambulatório e a internação hospitalar, tal como vinha sendo proposto na "A Casa”, hospital-dia privado de São Paulo. ${ }^{6}$ Em 1991, a equipe de acompanhantes terapêuticos de "A Casa" organiza uma coletânea de textos, a primeira edição brasileira sobre a prática que estamos investigando, intitulada A rua como espaço clínico.

A partir de 1992, com a promulgação das leis orgânicas que instituíram o Sistema Único Brasileiro, ocorre uma afirmação política dos direitos democráticos do cidadão brasileiro no âmbito da saúde pública e a concomitante expansão de

4. Instituições organizadoras do evento: o Centro de Atenção Psicossocial Prof. Luiz da Rocha Cerqueira - SP, Hospital-dia “A Casa” - SP, Projeto “Casa Verde” - RJ. Estiveram presentes representantes das seguintes instituições: Instituto de Psiquiatria - UFRJ, Hospital-dia da UFRJ, Clínica La Borde - França, Centro Psiquiátrico Pedro II - RJ, e Instituto de Medicina Social da UERJ.

5. No projeto original do Caps Luiz da Rocha Cerqueira foi mencionado os acompanhantes terapêuticos como membros da equipe técnica.

6. Editorial. I Encontro Sobre o Tratamento das Psicoses em Instituição. Secretaria Estadual de Saúde de São Paulo - SUDS I Região, Centro de Atenção Psicossocial Prof. Luiz da Rocha Cerqueira - SP, Hospital-dia “A Casa” - SP, Projeto Casa Verde - RJ (org.) 1990. 


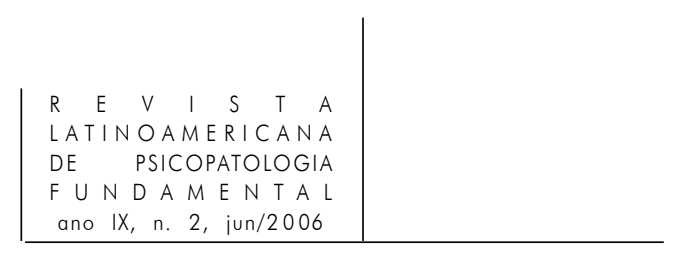

novos recursos e serviços ${ }^{7}$ que vieram compor a diversidade de possibilidades de cuidado e atenção às pessoas que padecem de problemas mentais. Hospitais-dia, hospitais-noite, núcleos e centros de atenção psicossocial, oficinas terapêuticas, pensões protegidas, cooperativas de trabalho, núcleos de oficina de geração de renda, são dispositivos alternativos que foram sendo criados para a construção de uma rede assistencial de base comunitária que garantisse a assistência multiprofissional e a preservação dos vínculos sociofamiliares (ibid., p. 4).

Em 1998, a Prefeitura Municipal de Porto Alegre firma um protocolo de cooperação com a Universidade Federal do Rio Grande do Sul para implementação de um projeto de acompanhamento terapêutico na rede pública de saúde municipal. Em 2000, o município de Belo Horizonte cria, através da portaria SMSA/SUS BH n. 004/2000, um Programa de Desospitalização para clientela de longa permanência de hospitais psiquiátricos e insere o acompanhamento terapêutico como estratégia clínica. Em abril de 2001, o Brasil conquista a Lei federal 10.216 que define os direitos e proteção das pessoas portadoras de transtornos mentais, incluindo o direito de ser tratada preferencialmente em serviços comunitários de saúde, visando alcançar sua recuperação pela inserção na família, no trabalho e na comunidade. Não havendo como retroceder estamos assistindo este processo de mudança, gradativo, mas persistente, que nos invoca a participação na construção destas novas redes ${ }^{8}$ que dão suporte e compõem o atual cenário da Reforma Psiquiátrica Brasileira.

Então, a pergunta: teria os acompanhantes terapêuticos uma função importante na tessitura das redes de cuidado em saúde mental? Sabemos que já existem algumas experiências relevantes acerca de nosso objeto de estudo e que produções teóricas vêm sendo desenvolvidas para afirmação do lugar e papel desse profissional. ${ }^{9}$ Contudo, iremos tratar de uma questão central que revela a

7. Portaria SNAS 224 promulgada em janeiro de 1992, que regula o funcionamento de todos os serviços públicos de saúde mental.

8. Para um maior aprofundamento sobre a noção de rede ver em: Pitta, Ana. Tecendo uma teia de cuidados em saúde mental. In: Venancio, Ana Teresa e Cavalcanti, Maria Tavares (orgs.). Saúde mental: campos, saberes e discursos. Rio de Janeiro: IPUB-CUCA/UFRJ, 2001, p. 277.

9. No Rio de Janeiro, em 2002, soubemos que acompanhantes terapêuticos foram oficialmente inseridos como profissionais de nível médio na rede pública do município de Quissamã através de um projeto aprovado pela câmara de vereadores desse município. Moreira em seu artigo (2003) propõe o uso do dispositivo acompanhamento terapêutico para aplicação junto ao idoso asilado em Betim (MG), e descreve os seguintes objetivos: possibilitar o resgate da identidade do idoso através do restabelecimento do vínculo com o cotidiano da cidade e suas histórias; restabelecer a inserção sociofamiliar do idoso através da quebra da exclusão social e do asilamento. 
preocupação deste estudo: o modelo de acompanhamento que construímos, com o desenrolar de sua história, nos aponta como direção única de aplicação apenas a prática privada? Sabemos que esta discussão não é nova e que, em nível local, a função do acompanhante terapêutico vem sendo utilizada na rede pública de saúde e mostrando-se relevante. Então, pensamos: estas experiências públicas já afirmam um novo destino para este profissional itinerante?

\section{Novos modos de cuidar}

O Campo da Atenção Psicossocial decorre da constatação de que o ambulatório de consultas não foi suficiente para impedir que pacientes graves continuassem a ter como destino a internação psiquiátrica e da percepção de que a doença mental implica uma dificuldade de expressão subjetiva que implica dificuldades concretas da vida que devem ser, elas próprias, objeto de atenção e cuidado (Tenório, 2001b, p. 93). Trata-se de ajudar o usuário em sua lida quotidiana por uma vida melhor, isso envolve o alívio dos sintomas, o apoio, a orientação à família, o suporte social, a criação de alternativas de trabalho, moradia e lazer, e a existência de uma referência institucional a que pacientes e familiares possam recorrer (Delgado, 1997, p. 42). Nesta assistência plural coexistem saberes científicos, dentre eles, médicos, psicológicos, sociais, e também leigos, etnográficos, culturais, que refletem diferentes modos de cuidar, de pensar o sofrimento psíquico, o homem e o mundo. Portanto, neste campo de assistência não são apenas os modelos teóricos e técnicos que prevalecem, mas também as premissas éticas que visam o cuidado e a não-exclusão das pessoas portadoras de transtornos mentais.

A nossa função terapêutica, ao menos com estes pacientes graves não seria muito mais acompanhá-los ao longo de suas trajetórias de vida, possibilitandolhes alguns encontros, ou pelo menos um testemunho para aquilo que eles dizem? (Cavalcanti, 1997, p. 194)

Segundo Cavalcanti (1997) a clínica da saúde mental, chamada clínica ampliada ou clínica da atenção psicossocial, deriva da história da psiquiatria. O saber psiquiátrico é fundador de todo o resto, e qualquer tensão ou ruptura entre diferentes teorias não colabora com o cuidado. É preciso lançar mão de diversos saberes, incluindo o saber da família e do próprio usuário. Este tratar é micropolítico e artesanal, caracterizado pela delicadeza e sensibilidade, onde o risco é uma constante (p. 153).

Em sua dissertação de mestrado Cavalcanti (1992) analisa a inserção da psicanálise nas instituições psiquiátricas, especialmente em uma dimensão ética e 


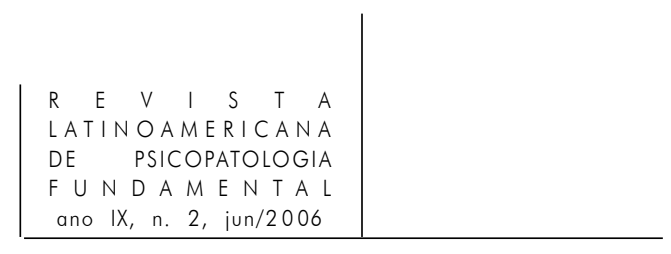

prática. Destaca as idéias de Jean Oury, ${ }^{10}$ que afirma não haver psiquiatria sem psicanálise. "Para ele a clínica psicanalítica faz parte da psiquiatria, uma vez que ao lidarmos com o sofrimento psíquico, portanto dentro da dimensão clínica, não há como desconhecer as contribuições da psicanálise, ou mesmo qualquer contribuição que possa ser útil ao contexto que nos encontramos” (p. 188). A questão do sofrimento psíquico, descreve Cavalcanti (1992), mais especialmente do transtorno psicótico, é a "perda de sentido na vida" que afeta a relação do sujeito com a realidade objetiva. No entanto, a autora distingue o esforço neurótico pela "busca por um sentido na vida", do que ocorre na psicose: "na psicose, esta perda de sentido se dá de uma forma muito mais concreta, avassaladora e desorganizadora de qualquer cotidiano, tanto para lidar com ela é preciso fazer coisas, ter aonde ir, poder passar de um lugar a outro” (p. 203). Nossa tarefa é, então "programar o acaso", ${ }^{11}$ devemos articular o tempo e a distância, a sensibilidade e a aproximação para que um bom encontro possa ocorrer e, neste, se possa produzir um "espaço de dizer". ${ }^{12}$

Como afirmamos, devemos contar com outros recursos que ampliam nosso olhar na clínica. São as soluções locais, são os laços de solidariedade e todas as possibilidades informais e imprevistas que possam surgir. Contar com estes recursos amplia, potencializa a clínica e desconstrói a figura do especialista como detentor do saber. O Encontro, ou o "bom encontro"13 (Corbisier, 2000) é o que desejamos, portanto o encontro é a ferramenta ${ }^{14}$ maior com que trabalhamos, que pressupõe uma posição ética desejante, que permita o acolhimento, o respeito ao outro e a disponibilidade. Para Cavalcanti (1992) a originalidade de Oury está no fato de procurar elaborar uma teoria que dê conta do universo coletivo. O objetivo desta clínica é possibilitar encontros nos espaços institucionais, encontros inesperados que possam vir a modificar pessoas, usuários e técnicos. Os espa-

10. Jean Oury, médico, psiquiatra, diretor da Clínica La Borde, instituição representada por Danielle Roulet no I Encontro sobre Tratamento das Psicoses em Instituição (1989) mencionado neste trabalho.

11. Frase que Jean Oury repete incessantemente ao longo de sua obra, segundo Cavalcanti, 1992, p. 195.

12. “A noção de 'espaço de dizer' aponta para a possibilidade de emergência de alguma coisa do que Lacan chama 'alíngua'. Diferente do que é simplesmente dito, Cavalcanti se refere à emergência de algo particular ao sujeito. Idem, p. 195.

13. “Um 'bom encontro' são aqueles capazes de aumentar nossa alegria e potência de nossos corpos à moda de Baruch Spinoza”. Apud Baremblitt (1998). In: Corbisier, C. 2000. RIPP: Quando escutar é preciso. Cadernos do IPUB, n. 17, UFRJ/IPUB, p. 67.

14. Cavalcanti (1992) utiliza o termo ferramenta em referência à analogia que Jean Oury faz em relação ao ofício dos lapidadores de pedras: “A ferramenta que utilizamos, no fundo, somos nós mesmos, pois quando encontramos com um paciente, o encontramos com todos os acontecimentos que nos marcaram, com as ferramentas que construímos, e é esse o material com que trabalhamos” (op. cit., p. 193). 
ços coletivos devem ser investidos de função terapêutica que possibilitem a produção de sentido e a emergência da singularidade de cada usuário. Devem se tornar espaços de vida, possibilitando a experiência de passagem de um lugar a outro, de um discurso a outro (p. 203), onde exista liberdade de circulação e heterogeneidade. Entendemos que mais do que fazer o indivíduo se interrogar sobre sua queixa ou sintoma, nossa tarefa é buscar o exercício ou a recuperação da capacidade de narrar fatos de sua própria vida. ${ }^{15}$ Neste sentido, partir do pensamento de Davoine (apud Cavalcanti, 1997), “... a utilidade da psicanálise consiste em possibilitar a inscrição, na história de cada um, de pedaços de tempo arrancados da história (...) para que estes pedaços não continuem assombrando o sujeito e falando por ele". Partindo da premissa lacaniana de que o inconsciente está presente nos efeitos do discurso e não escondido nas "profundezas do psiquismo", não há nada a ser buscado, o que temos a fazer é inventar sentidos para aquilo que se apresenta (p. 163). Portanto, nosso objetivo é acompanhar o indivíduo em seus gestos, na intenção de contar suas histórias que ele seja capaz de alinhavar o que for possível delas. A partir das suas recordações e revelações, que o sujeito possa vincular fatos, efeitos e tempos, a fim de reconhecer seus movimentos, seus passos e a direção que deseja tomar, para que nessa produção de sentido ele possa, processualmente, se deslocar de uma posição para outra, de uma função a outra, deixando envolver-se pelos movimentos e surpresas da vida cotidiana. Mas para que isso ocorra, temos que nos arriscar nesse trabalho de acompanhantes que somos, com a responsabilidade de permanecermos em estado de interesse e respeito, estando com o outro "na mesma paisagem” (Cavalcanti, 1992, p. 203).

\section{O território}

Caminante, no hay camino, se hace camino al andar.

Antonio Machado

"O esquizofrênico é o cavaleiro de parte alguma"16 (ibid., 2001). Em geral, o psicótico possui laços sociais enfraquecidos e por estar fora do discurso (Lacan,

15. Sobre a capacidade narrativa, Benjamin, Walter (1992) em "Reflexões sobre a obra de Nikolai Lesskov” (1936) In: Benjamin, Walter. Sobre arte, técnica, linguagem e política. Lisboa: Relógio D’água, 1992. O autor dá um exemplo radical do declínio da narração: o emudecimento dos soldados que voltavam da Primeira Guerra Mundial.

16. "Les schizophrenes sont les chevaliers de nulle part”. Cavalcanti (2001) menciona esta frase de Jean Oury. In: Cavalcanti, Maria Tavares et al. A psiquiatria e o social: aproximações e especificidades. In: Venâncio, Ana Teresa \& Cavalcanti, Maria Tavares (orgs.) Saúde mental: campos, saberes e discursos. Rio de Janeiro: IPUB-CUCA/UFRJ, 2001, p. 14. 


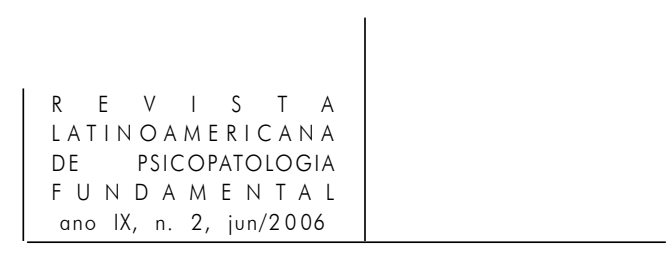

1955-56) apresenta dificuldades para passar de um ponto ao outro, de um lugar ou outro. Iremos pensar no percurso, utilizando nosso personagem, o acompanhante terapêutico, na travessia do sistema público de saúde, com vistas à integralidade da assistência, ao respeito pelo usuário e à inclusão social das pessoas que representam as demandas do campo da saúde mental.

Como afirma Delgado (2002, p. 35), ${ }^{17}$ no campo da saúde pública estamos acostumados a compreender a assistência em três níveis de complexidade: a atenção básica, atenção intermediária e a alta complexidade. ${ }^{18}$ Segundo o autor, esta "imagem mental de uma saúde pública em três andares funciona como um obstáculo para a construção de uma rede integral abrangente compatível com o fluxo dinâmico da clínica”. Tal divisão em três níveis produz distorções, dentre elas o elevado peso de investimentos no setor mais especializado da assistência: o setor hospitalar. E afirma que, o desafio da saúde pública no Brasil consiste em deslocar a atenção para o território e oferecer uma cobertura adequada e resolutiva na própria comunidade, entendendo que "o território não é o bairro e o domicílio do sujeito, mas o conjunto de referências socioculturais e econômicas que desenham a moldura de seu cotidiano, de seu projeto de vida, de sua inserção no mundo” (ibid., 1997, p. 42).

Como estratégia de assistência na atenção básica, o Programa de Saúde da Família (PSF), trouxe novidades importantes para o campo da saúde mental (Lancetti, 2000, p. 18.). Este programa, associado ao programa de agentes comunitários de saúde (PACs), propõe que o usuário seja procurado onde ele está e vive. Trabalha com a adscrição da clientela através do cadastramento das pessoas que moram em uma determinada área e revela uma principal diferença: o atendimento é oferecido a partir das necessidades encontradas e não pela demanda. O imperativo é buscar encontrar as soluções para os problemas no próprio local, a fim de evitar encaminhamentos. Desta forma, a equipe passa a ser a referência do tratamento e não o serviço ou o saber médico. Em referência à experiência pioneira de implantação do programa em São Paulo, ${ }^{19}$ Lancetti

17. Delgado, Pedro Gabriel. Saúde mental na rede básica. Artigo apresentado no Seminário Internacional sobre Atenção Primária em Saúde Mental, Organização Panamericana de Saúde e Ministério da Saúde realizado no Rio de Janeiro em abril de 2002.

18. O autor refere-se às "ações de saúde que se realizam na atenção primária ou rede básica - aí incluindo o Programa de Saúde da Família; ações que se dão em um nível de complexidade intermediária - os ambulatórios e pequenas unidades de atendimento médico cirúrgico; e ações mais complexas - como as cirurgias maiores ou mais complicadas, os exames complementares sofisticados, os tratamentos muito longos e dispendiosos e as internações especializadas." Delgado, 2002.

19. Programa Qualis/PSF - SP. 
(p. 19) conta que foram criadas equipes volantes para cobrir a assistência em saúde mental no território, e menciona que o objetivo do programa era habilitálos para operarem como amigos qualificados, utilizando este conceito como um retorno ao que deu origem à profissão do acompanhante terapêutico (p. 21, nota 9). "Muitos agentes comunitários destacaram-se funcionando verdadeiramente como amigos qualificados, lançando mão de ferramentas simples do cotidiano, num corpo a corpo capaz de romper resistências e encurtar distâncias” (Gonçalves, 2000, p. 114).

Pensando nesta nova arquitetura dos serviços de saúde mental, os CAPS (Centros de Atenção Psicossocial) são considerados estratégicos para a construção da rede que estamos falando. Estes serviços de atenção diária são lugares que devem se constituir como referência para o tratamento, acompanhamento e reinserção de pessoas com transtornos mentais, e também àquelas que fazem uso prejudicial de álcool e outras drogas. No entanto, uma questão se mostra pertinente: estaremos centralizando a assistência em saúde mental nos CAPS? E ainda: corremos o risco de nos fechar? Cavalcanti (1992, cap. IV, p. 238, nota 6) afirma que "a inclinação natural de toda a coletividade é seu fechamento". Segundo a autora, diariamente lutamos por nosso território, partimos na defesa de nossas idéias, de nossos usuários, criamos sistemas de defesa, formando "agregados de pequenos reinos que produzem estes fenômenos institucionais do tipo paranóico” (p. 210), e neste cenário toda possibilidade de dimensão terapêutica cai por terra. Sabemos que estes fenômenos vêm ocorrendo muito freqüentemente nos Caps que conhecemos. Sentimos dificuldades em estender nossos olhares para além do que conhecemos. Sabemos como, também para nós, é complicado fazer articular nossa rede de relações e nos manter abertos para a formação de novos vínculos de confiança com outros profissionais, instituições e serviços que venham contribuir para ampliação do cuidado que desejamos oferecer.

Como ressaltam Verztman \& Gutman (2001) “a clínica deve ser nosso ponto de partida e não de chegada”. E pensando com esses autores, não deveria ser o CAPS um espaço transacional que possibilitasse um "brincar compartilhado" em que o sujeito pudesse sair de uma situação de dependência para o desenvolvimento da capacidade de estar só, em outras palavras, de ganho de autonomia? Esta crescente preocupação vem ao encontro do que imaginamos ser uma função importante do acompanhante terapêutico neste seu "circular pelo território". Como uma "modalidade de intervenção no social" (Maia e Pirim, 1997, p. 7), teria o AT algo a contribuir para que ocorra um movimento do Caps para fora, para a vida? Teria o AT função de acompanhar o usuário, sendo ele adulto, idoso ou criança, psicótico, neurótico grave ou usuário de drogas, em suas inferências pelo mundo a procura de trabalho, e também, moradia e lazer? 


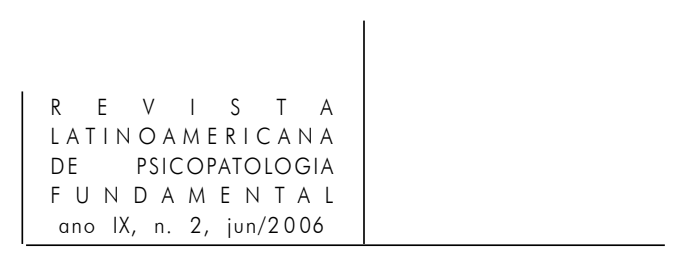

Com relação aos Programas de Desinstitucionalização de pacientes que residem em hospitais psiquiátricos, a implantação de serviços residenciais terapêuticos e a expansão do programa de bolsa-auxílio "De volta pra casa", ${ }^{20}$ teriam os acompanhantes algo a contribuir na conexão com os espaços extramuros? Nestas tarefas que nos inquietam e desafiam, concordamos, mais uma vez, com Cavalcanti (1997):

Talvez não devêssemos abrir mão de nenhum tipo de estrutura de trabalho e sim transformá-los na direção que nos interessa, podendo utilizá-los na medida de nosso interesse e necessidade. (p. 152, nota 2)

Podemos, ainda, nos interrogar acerca de outra noção, cara às novas práticas em saúde mental: a de projeto terapêutico (Tenório, 2001). O autor destaca que essa noção introduz a dimensão de que cada tratamento é singular, devendo ser avaliado caso a caso, e a todo momento (p. 66). O projeto terapêutico individual descreve o percurso de tratamento do usuário e as metas do trabalho. Através desse documento, é possível analisar as demandas e necessidades, verificar quais recursos dispomos e quais se revelam mais adequados para compor a prática do cuidado oferecido.

Portanto, sejam agentes comunitários de saúde, técnicos de referência dos usuários do CAPS ou cuidadores dos serviços residenciais terapêuticos, devemos somente nos ater ao fato de que, muitas vezes, é necessário nos deslocarmos para onde o problema está, a fim de participarmos da situação vivida e produzir acontecimentos. Talvez esta prática traduza o que Deleuze (apud Lancetti, 2000, p. 37) descreve como clínica cartográfica. Na travessia de uma caminhada se constitui uma clínica tecida por um entremeado de percursos em um deslocamento entre um mapa e outro. A nosso ver, esta clínica atende às diretrizes do Sistema Único de Saúde Brasileiro e possibilita a real execução das políticas que buscam integralidade da assistência a partir do conceito de cobertura no território. Os acompanhantes são aqueles que promovem encontros e agenciamentos de desejos, durante o percurso de diferentes caminhos. Este personagem está "em cena”, “em ação", no momento em que o mundo toma contorno. "O acontecimento é uma situação de ruptura que exige um novo posicionamento e uma fidelidade à nova ordem criada” (Moreira, 2003, p. 58). O AT, com sua presença física, cria densidade às situações vividas e pode auxiliar o sujeito a sustentar novos posiciona-

20. Para um maior aprofundamento sobre o programa "De volta pra casa" e os serviços residenciais terapêuticos, consultar Brasil, MS/SAS (1994) Legislação em Saúde Mental: 1990-2004, 5. ed. ampliada - Brasília: Ministério da Saúde, mais especialmente à Lei n. 10,708 de 31 de julho de 2003 e à Portaria GM, n. 106 de 11 de fevereiro de 2000. 
mentos frente às diferentes configurações que a vida toma. Mas para isso é preciso deixar o tempo acontecer, deixar que o momento se faça potência. A partir do espaço entre dois, entre um significante e outro, entre um silêncio e outro, entre um acontecimento e outro. Lado a lado, o acompanhante permite que o sujeito caminhe neste deslocamento físico onde as mudanças de paisagens tornamse recursos fundamentais nesta prática terapêutica. Nem sempre há algo a dizer, o acontecimento da palavra se dá de forma natural, visto que ambos estão sendo afetados pela paisagem que os cerca. A partir daí, torna-se possível a tessitura de um quadro de referência, onde os novos tempos venham a representar a mudança, o tratamento, o trabalho, a casa, a nova vida.

O que propomos é o uso de uma ferramenta plástica que pode funcionar a partir do princípio da necessidade e não da demanda. O acompanhante move, leva e traz, vive, reconhece e descola. Este agente põe a funcionar, trabalha como tentáculos da instituição, é responsável por estabelecer conexões entre as agendas de eventos culturais, sociais e artísticos de uma cidade. É um profissional que está fora e ao mesmo tempo está dentro, penso que está dentro justamente porque está fora. Ou seja, é aquele que pode induzir práticas, que se move com esperança de que algo novo se produza, pois, aposta no contato com o diferente e faz suscitar acontecimentos, produzindo o nascimento de novos espaços.

Na saúde mental trabalhamos no campo das idéias, são nossas convicções, reflexões e enfrentamentos que determinam os tempos e ritmos das transformações que almejamos. Estamos falando de estratégias que possam traduzir um sentido, uma direção de responsabilidade. Fazemos o que é possível no momento, porém, nossas ações traduzem um sentido, uma direção e um posicionamento. O que propomos não é a formação e capacitação de novos paramédicos ou novos agentes de saúde. Estamos propondo táticas que promovam a formação de alianças, conexões diretas com aqueles que são objeto do nosso cuidado. Sejam eles pessoas longamente internadas que estão aguardando sua alta, pessoas que passaram por uma crise em decorrência de um transtorno mental ou do uso abusivo do álcool ou das drogas, pessoas que irão morar em serviços residenciais terapêuticos, usuários que estão sendo inseridos no serviço, ou mesmo aqueles que deixaram de freqüentá-lo.

\section{A questão do risco}

Marazina (1991, p. 122-3) afirma que "o lugar do acompanhante terapêutico é o mesmo lugar do extraterrestre, daquele que tenta, dentro do possível, derrubar o muro e sair com a loucura à rua, a loucura do paciente e a 


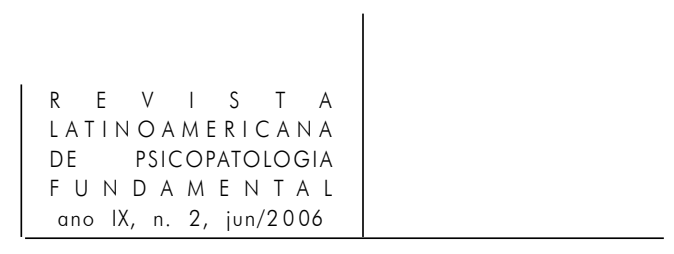

sua, e se expõe às numerosas articulações dessa situação, mas fazendo dela o seu lugar de potência”. Para a autora é neste "fio de navalha" que trabalha o acompanhante e afirma que este profissional convive com altos riscos, pois, seu corpo recebe todo o impacto da loucura como único continente. "Daí a necessidade, da pertinência institucional, seja uma equipe ou uma instituição de tratamento, para poder trabalhar e depositar, nesse continente, as próprias ansiedades psicóticas, que são o motor e o emperramento do trabalho" (p. 123). Neste sentido, Marazina (ibid.) destaca a importância da implicação do acompanhante na instituição que lhe possibilita suporte. Ou seja, para além de nossas próprias certezas ou dúvidas individuais, devemos construir coletivamente as diretrizes do tratamento, a partir de pressupostos do trabalho e das políticas que se colocam a este serviço.

Iremos mencionar outra dimensão do risco que corremos: considerando que o trabalho em saúde mental requer a reconstrução ou até criação da vida cotidiana, de que forma isto se dará? Que contorno a vida do usuário pode tomar? O problema se dá quando enfrentamos esta tarefa a partir do que queremos, e em geral a partir das nossas próprias referências sociais, culturais e éticas. Estamos impregnados do modelo de cidadão autônomo, determinado como atributo fundamental da modernidade, e em geral associado ao padrão de cura em psiquiatria. Como nos diz Carrozzo: "O problema é podermos agüentar a singularidade deste paciente, poder validar o que é que ele gostaria de construir como seu cotidiano, seja dentro ou fora da instituição" (I Encontro Sobre o Tratamento das Psicoses em Instituição, 1989). Neste sentido, os acompanhantes terapêuticos necessitam ser pessoas que lutem pela não formalização de conceitos, ou seja, que não reconheçam a realidade dada como natural. A aposta de que para além da crise, ali há um sujeito aguardando para se pronunciar, ajuda a nos despir de preconceitos e nos coloca em posição de disponibilidade e comprometimento frente à singularidade destes sujeitos. Pensamos que é necessário oferecer um olhar curioso e humano para que possamos trabalhar como formigas operárias, sem a preocupação de consertar as coisas e sim acompanhá-las, construindo jogos possíveis a partir de regras que venham a ser construídas neste percurso.

Podemos imaginar um estrangeiro que chega a uma nova cidade e de alguma forma precisa compreender alguns códigos, decifrar algumas cartografias que possibilitem sua circulação e percepção desta cidade, assim acontece no acompanhamento terapêutico. (Cabral e Belloc, 2003, p. 3) $)^{21}$

21. Cabral, K. V. e Belloc, M. M. O acompanhamento terapêutico como dispositivo da reforma psiquiátrica. Artigo apresentado no Tercer Congreso Argentino y Primer Congreso Iberoamericano de Acompañamiento Terapeutico, Buenos Aires - Ar, novembro de 2003. O 
Um evento novo produz uma resposta nova, acompanhantes caminham juntos aos acompanhados e juntos suam suas camisas. Experiências diversificadas oferecem ao sujeito a possibilidade de sentir-se parte de uma tarefa que lhe indica sua própria importância. Nestes movimentos espontâneos, flexíveis e geradores de identidades, negociações particulares, trocas e laços sociais podem se criar. Pensamos que só a partir daí poderemos efetivamente, enfrentar a desqualificação de que são vítimas nossos usuários. A partir da possibilidade de construção de novas modalidades de relação entre aqueles que coabitam um território na promoção de um processo de reconstrução de laços solidários entre os pares.

Ao sairmos à rua deparamo-nos com a nossa percepção de cidade, tendemos a seguir trajetos conhecidos que nos parecem mais seguros. Para que possamos construir novos caminhos e produzir mudanças junto a estas pessoas é necessário nos aventurarmos a permitir que a partir deste encontro com o outro, uma nova cidade, também para nós, possa emergir. É preciso deixar que nossa percepção se altere, observando fragmentos, traços nunca antes percebidos, seu colorido, sua feiúra etc. (p. 3) Entendemos que desta forma podem surgir os tais "espaços de dizer” de que falamos, cada situação pode ser vista como momento novo a ser trabalhado, ou simplesmente vivido. A princípio, não existe situação totalmente boa ou totalmente ruim, existem, sim, situações específicas. É preciso distinguir a singularidade do sujeito da emergência da singularidade do momento vivido. Falamos dos acontecimentos e de tudo que nos afeta à nossa volta. Entendemos que quando este encontro se dá, ocorre uma experiência subjetiva que produz uma mudança que impele o sujeito a pronunciar-se. Ao provocar o acaso deste momento, ocorre a aposta implícita de que algo se ponha a mover e que daí se dê um processo de criação conjunta, com vistas à possibilidade do uso da palavra e a inscrição do sujeito.

artigo trata da experiência de um curso sobre Acompanhamento Terapêutico, realizado na Escola de Saúde Pública da Secretaria de Saúde do Estado Rio Grande do Sul, dirigido a profissionais da rede pública e coordenado pela Prof. Analice Palombini e Regina Moura Castilho. E também do processo de assessoria a um grupo de trabalhadores do Hospital Psiquiátrico São Pedro, vinculado à referida Secretaria, que enfrentou o desafio de “acompanhar” os usuários desse serviço na passagem para o residencial terapêutico Morada São Pedro. 


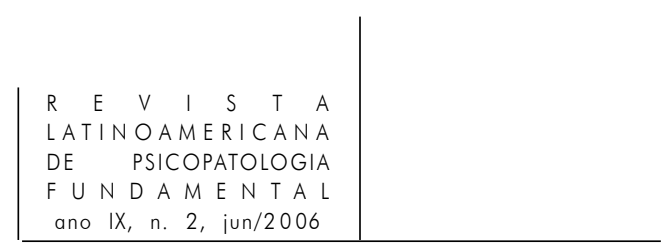

\section{Considerações finais}

Acompañar y ser acompañados se transforma en un proceso por el cual somos reconocidos en nuestra individualidad, construyendo una imagen de cuanto valemos para los demás. Se constituye un verdadero juego de espejos en el que podemos mirarnos, mirar y ser mirados. El acompañamiento humano da idea de un movimiento protagonizado por personas que se ocupan de alguien cuya estabilidad está en peligro, cuya firmeza requiere de apoyos para transitar la vida. (Pellegrini, 2003) $)^{22}$

A proposta experimental de inserção de acompanhantes terapêuticos na rede pública de saúde reconhece e afirma o princípio ético da integralidade da assistência em saúde mental. Pensamos que esta prática pode vir a se constituir através de um conjunto de ações combinadas e articuladas entre si que possuam em seu eixo o movimento e a circulação no território. Com a finalidade de encontrar soluções locais e produzir agenciamentos, os acompanhantes terapêuticos se colocam em uma posição que pressupõe proximidade e implica o estabelecimento de conexões diretas com a população adstrita e o trânsito por diferentes territórios existenciais.

Em sua origem vimos que esta prática nasceu a partir da necessidade de médicos e psicanalistas em estender olhares para além dos consultórios e instituições. Neste sentido, para além de uma técnica específica, entendemos o acompanhamento terapêutico como um campo de intervenção (Reis, 1995, p. 5). Percorremos a história deste agente que buscava criar um clima de informalidades nas instituições fechadas. Vimos que em determinado momento da história o AT foi o representante da abertura dos hospitais e das clínicas privadas. Buscava-se um maior estreitamento das relações entre os que estavam para tratar e os assistidos. O saber menos técnico deste profissional em formação possibilitou que outros recursos fossem utilizados na clínica psiquiátrica.

No decorrer deste trabalho uma questão percorreu nossos questionamentos. Pensamos sobre a possibilidade de fazer prosseguir a história dos acompanhantes terapêuticos para o âmbito público da assistência em saúde mental. Concluímos que para que isto se torne possível é necessário pensar que parte do nosso instrumental terapêutico está determinada pela simples condição humana e pelo reconhecimento da aprendizagem que a vida cotidiana nos oferece. Devemos

22. Jorge Luis Pellegrini, diretor do Hospital Escuela de Salud Mental de San Luis/2003. Comunicação oral, Tercer Congreso Argentino y Primer Congreso Ibero-americano de Acompañamiento Terapéutico, realizado nos dias 28, 29 e 30 de novembro de 2003 na Facultad de Medicina de Buenos Aires, Argentina. 
considerar que parte do que somos é constituído por nossas histórias, lembranças e raízes que colorem de significados as experiências e nos enriquecem. Se partirmos deste eixo, ampliamos o foco e poderemos incluir os saberes populares como recursos terapêuticos. Ou seja, para diferentes modos de vida, diferentes modos de cuidado.

Os acompanhantes terapêuticos da reforma psiquiátrica de hoje são agentes de saúde que se dispõem a participar da vida, das escolhas e das vivências de pessoas que necessitam serem acompanhadas na travessia de algum momento específico de suas vidas. Estes agentes podem garantir que projetos e ações públicas obedeçam à direção, aos ritmos e tempos da clínica na vida cotidiana, lançando mão do imprevisível e do poder de escuta. Mas, acima de tudo, acreditamos que os acompanhantes terapêuticos podem ser verdadeiros transformadores sociais na promoção de ações mais solidárias e tolerantes em relação às pessoas que convivem com o sofrimento mental.

Como afirmam Cabral e Belloc (2003), ${ }^{23}$ através desta modalidade de atenção em saúde é possível investir intensamente na constituição de um enlace entre sujeito e social. O acompanhante, em uma intervenção clínica, busca descobrir o que faz sentido para aquele sujeito singular e o que pode ser considerado dispositivo a ser recortado daquele social para auxiliar o sujeito na construção de sua rede. Esta construção se torna possível na medida em que é possível acompanhar o paciente em seus pontos discursivos, entre um espaço e/ou outro, nesta articulação dinâmica, clínica, política e social deste entorno que se move e que a todo o momento produz novas realidades. Os acompanhantes produzem alianças humanas com pessoas que possuem o direito de construir um lugar possível para si próprias e que necessitam participar do fluxo da vida.

\section{Referências}

Benjamin, Walter. Sobre arte, técnica, linguagem e política. Lisboa: Relógio D’água, 1992.

23. Cabral, K. V. e Belloc, M. M. O acompanhamento terapêutico como dispositivo da reforma psiquiátrica. Artigo apresentado no Tercer Congreso Argentino y Primer Congreso Iberoamericano de Acompañamiento Terapeutico, Buenos Aires-Ar, novembro de 2003 e publicado, recentemente, em Palombin, Analice de Lima, et al. Acompanhamento terapêutico na rede pública: a clínica em movimento. Porto Alegre: UFRGS, 2004. 


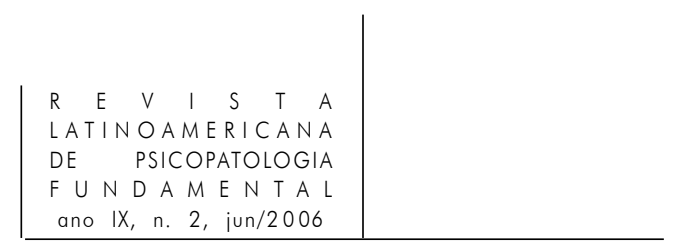

CARrozzo, Nelson Luiz. Apresentação. In: Equipe de Acompanhantes Terapêuticos do Hospital-dia A Casa (org.). A rua como espaço clínico, acompanhamento terapêutico. São Paulo: Escuta, 1991. p. 11-3.

CavalCanti, Maria Tavares. O tear das cinzas. Um estudo sobre as relações entre a psicose e instituições psiquiátrica. 1992. 368 p. Dissertação (mestrado). Universidade Federal de Rio de Janeiro.

A trama do tear sobre o tratar em psiquiatria. 1997. 287p. Tese (Doutorado). Universidade Federal do Rio de Janeiro.

Cavalcanti, Maria Tavares et al. A psiquiatria e o social: aproximações e especificidades. In: Venâncio, Ana Teresa \& CaVAlCAnti, Maria Tavares (orgs.). Saúde mental: campos, saberes e discursos. Rio de Janeiro: IPUB-CUCA/UFRJ, 2001. p. 13-38.

CoRBISIER, Cláudia. RIPP: Quando escutar é preciso. Cadernos do IPUB. Rio de Janeiro, n. 17, p. 59-69, 2000.

Delgado, Pedro Gabriel. As razões da tutela. Psiquiatria, justiça e cidadania do louco no Brasil. Rio de Janeiro: TeCorá, 1992. p. 29-53.

A psiquiatria no território: construindo uma rede de atenção psicossocial. Saúde em foco: informe epidemiológico em saúde coletiva, Rio de Janeiro, ano IV, n. 16, p. 41-3, nov. 1997.

Editorial. Legislação em Saúde Mental 1990-2004. Série Legislação em Saúde. Ministério da Saúde do Brasil, Brasília, n. 5, 2004.

IвRAнiм, Cesar. Do louco à loucura: o percurso do auxiliar psiquiátrico no Rio de Janeiro. In: Equipe de Acompanhantes Terapêuticos do Hospital-dia A Casa (orgs.). A rua como espaço clínico, acompanhamento terapêutico. São Paulo: Escuta, 1991. p. 43-51.

Lacan, Jacques (1955-56). O seminário. Livro 3. As psicoses. Rio de Janeiro: Jorge Zahar, 1985.

LancetTI, Antonio. Saúde mental nas entranhas da metrópole. Saúde Loucura, saúde mental e saúde da família, São Paulo: Hucitec, n. 7, p. 11-53, 2000.

MAIA, Marisa Schargel \& PiRIM, Mírian. Em busca de uma singularidade: uma proposta clínica no processo de reinserção social. In: VenÂncio, Ana Teresa et al. O campo da atenção psicossocial: anais do I Congresso de Saúde Mental do Estado do Rio de Janeiro. Rio de Janeiro, Instituto Franco Basaglia: TeCorá, 1997. p. 5-15.

Marazina, Isabel. Comentários. In: Equipe de Acompanhantes Terapêuticos do Hospital-dia A Casa (orgs.). A rua como espaço clínico, acompanhamento terapêutico. São Paulo: Escuta, 1991. p. 119-24.

Mauer, Susana Kuras \& Resnizky, Silvia. Acompañantes Terapéuticos, actualización teórico-clínica. Buenos Aires: Letra Viva, 2003.

Acompanhantes terapêuticos e pacientes psicóticos: manual introdutório a uma estratégia clínica. Campinas: Papirus, 1987. 
Moreira, Jaqueline de Oliveira. Matrizes históricas do acompanhamento terapêutico: raízes e conceituação. Pulsional Revista de Psicanálise, São Paulo, ano XVI, n. 173, p. 48-61, 2003.

Pitta, Ana. Tecendo uma teia de cuidados em saúde mental. In: VenÂncio, Ana Teresa e Cavalcanti, Maria Tavares (orgs.). Saúde mental: campos, saberes e discursos. Rio de Janeiro: IPUB-CUCA/UFRJ, 2001. p. 277-82.

Ribeiro, Thais da Cruz Carneiro. Acompanhar é uma barra: considerações teóricas e clínicas sobre o acompanhamento psicoterápico. Psicologia Ciência e Profissão. Brasília, ano XXII, n. 2, p. 78-87, 2002.

Reis, Raymundo. Acompanhamento terapêutico: emergência e trajetória histórica de uma prática em saúde mental no Rio de Janeiro. 1995. 175p. Dissertação (mestrado em Psicologia clínica). Pontifícia Universidade Católica do Rio de Janeiro.

TeIXeIrA, Manuel Olavo. Do asilo ao Hospital-dia: considerações sobre atenção em psiquiatria e saúde mental. Saúde em foco: informe epidemiológico em saúde coletiva. Rio de Janeiro, ano IV, n. 16, p. 3-4, nov. 1997.

TENóRIo, Fernando. A psicanálise e a clínica da reforma psiquiátrica. Rio de Janeiro: Rios Ambiciosos, 2001.

Reforma psiquiátrica e psicanálise: um trabalho necessário. In: FigueIredo, A. C.; Cavalcanti, M. T. (org.). A reforma psiquiátrica e os desafios da desinstitucionalização - contribuições à III Conferência Nacional de Saúde Mental. Rio de Janeiro: CUCA/IPUB/UFRJ, 2001. p. 85-101.

Verztman, J. S.; Gutman, G. (2001). A clínica dos espaços coletivos e as psicoses. In: VenÂncio, Ana Teresa e Cavalcanti, Maria Tavares (org.). Saúde mental: campos, saberes e discursos. Rio de Janeiro: IPUB-CUCA/UFRJ, 2001. p. 39-72.

\section{Resumos}

Este estudio busca reflexionar sobre el Acompañamiento Terapéutico como una modalidad de asistencia destinada a personas con trastornos mentales. A partir de sus orígenes y de su desarrollo a lo largo de la historia, buscamos construir articulaciones posibles de esta práctica con las actuales directrices éticas y clínicas de las políticas públicas brasileñas, con el objetivo que sea percibida como una opción estratégica a ser incorporada al servicio de asistencia pública en la salud mental.

Palabras claves: Acompanãmiento terapéutico, atención psico-social, integralidad, território

Cet étude vise à réfléchir sur l'accompagnement thérapeutique comme une modalité de soin destinée aux personnes avec des troubles mentales. Depuis origines 


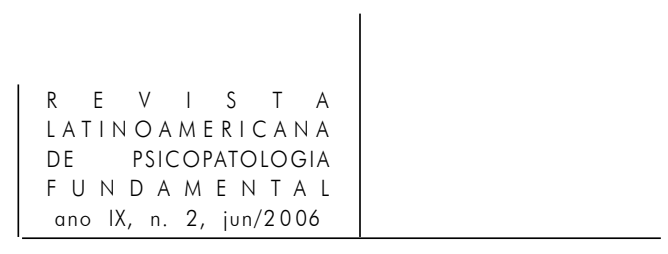

et tout au long de son développement, nous recherchons les ponts possibles avec les lignes éthiques et cliniques de la politique de santé publique courante, le regardant en tant qu'option stratégique à insérer dans les soins publiques en santé mentale.

Mots clés: Accompagnement thérapeutique, integralité, soins psychossociales, territoire

This study discusses the topic of psychotherapeutic escorting as a modality of assistance for persons with mental disorders. The authors take up the origins of this type of practice and briefly describe its history, in the search for ways to coordinate this practice in Brazilian public health policies, as a strategic option among the types of therapy offered in the area of mental health.

Key words: Psychotherapeutic escorting, integrality, outpatient facilities, mental health care system 